\title{
Sobre as professoras dos primeiros anos e suas práticas: influências da formação
}

\section{About the teachers of early years and their practices: influences of training}

\author{
Arthane Menezes Figueirêdo ${ }^{1}$ \\ Graça Aparecida Cicillini²
}

\begin{abstract}
RESUMO
O presente estudo é um recorte da pesquisa de doutorado em Educação, apresentada à Universidade Federal de Uberlândia (UFU), e refere-se a uma reflexão sobre as concepções de duas professores/as dos primeiros anos do Ensino Fundamental no que tange às influências de sua formação inicial para as práticas que realizam. A pesquisa seguiu um viés qualitativo e partiu da seguinte questão norteadora: "Como professoras que foram formadas no Curso de Pedagogia relacionam sua formação inicial às práticas que realizam em turmas dos primeiros anos do Ensino Fundamental?" A metodologia utilizada foi a entrevista aberta semiestruturada, realizada de forma oral, com gravação das falas e transcrição literal das informações. A análise buscou compreender se os saberes formativos são percebidos pelas professoras no contexto do trabalho que realizam. Como resultado, as professoras destacam influências positivas e negativas da formação: entre as positivas, o estudo de diversas teorias voltadas ao ensino e à aprendizagem dos conceitos e, entre as negativas, as limitações dos conhecimentos específicos das disciplinas escolares, em razão dos poucos estudos durante a formação. Como conclusão, observamos que os saberes da formação são considerados fundamentais para uma boa atuação profissional, porém, há ressentimento em relação às dificuldades com os conceitos escolares, que são atribuídas à falta de estudos específicos na formação inicial.
\end{abstract}

Palavras-chaves: formação inicial; curso de Pedagogia; professoras dos primeiros anos do Ensino Fundamental.

DOI: $10.1590 / 0104-4060.45144$

1 Universidade Federal do Amapá. Macapá, Amapá, Brasil. Rodovia Juscelino Kubitscheck, km 02, s/n . Jardim Marco Zero. CEP: 68903-419.E-mail: arthane@gmail.com

2 Universidade Federal de Uberlândia. Uberlândia, Minas Gerais, Brasil. Av. João Naves de Ávila, nº 2121 - Santa Mônica. CEP: 38.408-100.E-mail: gacicillini@gmail.com 


\begin{abstract}
This study is part of a $\mathrm{PhD}$ research in Education presented to the Federal University of Uberlândia (UFU) and refers to a reflection on the concepts of two teachers from the early years of Elementary School in relation to the influence of their first training to the practices they perform. The research followed a qualitative bias and left the following question: "How teachers who were trained in a Pedagogy Course relate their initial training to the practices they take in courses of the first years of Elementary School?" The methodology used was the semi-structured open interview, which was conducted orally, with recording of the speech and literal transcription of the information. The analysis sought to understand whether the training knowledge is perceived by teachers in the context of their work. As a result, the teachers highlight positive and negative influences of training: among the positive ones, there is the study of various theories focused on the teaching and learning of concepts and, among the negative ones, there are the limitations of the specific knowledge of school subjects in reason of the few studies during training. In conclusion, we observed that the knowledge of training is considered essential to a good professional practice, however, there is resentment about the difficulties with school concepts, which are attributed to the lack of specific studies in initial formation.
\end{abstract}

Keywords: initial training; Faculty of Education; teachers in the early years of Elementary School.

\title{
Introdução
}

A escola é a instituição que tem por objetivo a socialização dos conhecimentos científicos e culturais da sociedade e os professores utilizam diversos tipos de saberes no desenvolvimento de suas aulas que visam possibilitar aos alunos o pleno desenvolvimento de suas capacidades e que serão em algum momento aplicados à sociedade em que vivem.

Cicillini (2010) destaca que a constituição da identidade do professor pressupõe uma constante reflexão em torno das ações que se desenvolvem nos cursos de formação de professores e que cada contexto é único, complexo e mutável, mas precisam possibilitar aos futuros profissionais as condições necessárias à realização de um trabalho fundamental para a sociedade atual.

Freire (2005) atribuiu aos docentes a possibilidade de ensinar os conceitos científicos de forma crítica, com vistas a superar as práticas fundamentadas em uma concepção de educação à qual denominou como bancária, isto é, quando os alunos são tratados como receptores passivos e acríticos do conhecimento histo- 
ricamente construído na sociedade, e a formação desses profissionais influencia substancialmente a forma como os profissionais atuam, uma vez que " $[\ldots]$ o saber docente é um saber de relação que é construído mediante um processo que articula dialeticamente teoria e prática”. (FIORENTINI; COSTA, 2009, p. 314).

De acordo com Freire (2011, p. 78), "[...] ninguém educa ninguém, como tampouco ninguém se educa a si mesmo: os homens se educam em comunhão, mediatizados pelo mundo". Dessa forma, as relações educativas precisam envolver tanto professores quanto alunos, pois estes sujeitos do conhecimento aprendem mutuamente por meio da interação. Nesse sentido,

A construção do fazer-se dos professores e professoras dá-se num processo relacional, ou seja, constrói-se na interação com os outros, i.é, com os professores universitários, os colegas de trabalho, os alunos, com os autores dos livros, com a comunidade escolar, ou ainda, outros situados em diferentes loci da produção de saberes, na troca de experiências, no diálogo constante é que ocorre a feitura profissional do professor. Este processo, portanto, dá-se de maneira social e nunca individual; e, em sendo social, não pode ser homogêneo. (PAIM, 2005, p. 144).

Gauthier et al. (1998) consideram a existência de um repertório de conhecimentos ou saberes que se voltam à profissionalização dos docentes, que precisam fazer parte da formação, que se apresentam em seis categorias, às quais denominou como saberes: disciplinares, curriculares, das ciências da educação, da tradição pedagógica, experienciais e os da ação pedagógica.

Ressaltam os autores que os conjuntos de saberes são complementares entre si e integram o conjunto de conhecimentos individuais, envolvendo relações familiares, conhecimentos científicos e culturais apropriados pelos sujeitos, valores, crenças, concepções e práticas. Assim, todos os saberes que compõem esse repertório de conhecimentos são importantes para uma boa atuação do profissional, pois:

Em suas atividades pedagógicas diárias, os professores planejam, executam o plano didático, escolhem as metodologias que julgam condizentes, elaboram as tarefas para os alunos, administram a sala de aula mantendo a ordem e a disciplina e constroem os instrumentos de avaliação. Em outras palavras, os professores tratam da gestão da matéria e da gestão da sala de aula e, por isso, necessitam utilizar diferentes "saberes" necessários à consecução dos objetivos previamente definidos. (CUNHA, 2007, p. 6-7). 
Os conhecimentos profissionais da docência são considerados como progressivos e complementares, logo, colocá-los em prática implica na capacidade dos professores em utilizar um pouco de "[...] improvisação e adaptação a situações novas e únicas, que exigem do profissional reflexão e discernimento para que possa, não só compreender o problema, como também organizar e esclarecer os objetivos almejados e os meios a serem usados para atingi-los". (TARDIF, 2000, p. 7).

Assim, a atuação dos(as) docentes demanda que estes profissionais sejam envolvidos no contexto sociopolítico da sociedade, possuam um repertório de conhecimentos da profissão amplo e sejam capazes de lidar com eles de forma integrada ao contexto sociocultural, além de dominar conhecimentos específicos do processo de ensino e aprendizagem; saberes que, no contexto da atuação profissional docente, tornam-se ferramentas importantes para uma atuação comprometida com a formação de cidadãos e cidadãs conscientes, críticos e atuantes socialmente.

Diante do exposto, o presente estudo teve como propósito responder ao seguinte questionamento: "Como professoras que foram formadas no Curso de Pedagogia relacionam sua formação inicial às práticas que realizam em turmas dos primeiros anos do Ensino Fundamental?"

O problema se justifica pelos questionamentos às práticas escolares de professores dos primeiros anos, seja pelos resultados pouco expressivos nas avaliações nacionais ou pelos relatos de estudos que apontam problemas na organização dos currículos do Curso de Pedagogia, no que tange às fragilidades de estudos voltados para os conhecimentos específicos das disciplinas escolares dos primeiros anos. (LIBÂNEO, 2010; GATTI, 2010).

Para alcançar tal desígnio, realizamos a pesquisa em duas escolas de Ensino Fundamental, com o objetivo de conhecer e analisar as convergências e divergências nas falas de professoras dos primeiros anos, graduadas em Pedagogia, sobre as influências de suas formações para as práticas que desenvolvem como professoras desse segmento.

\section{Trilhas metodológicas do estudo}

A pesquisa foi realizada em duas escolas da rede pública de ensino do interior de Minas Gerais, tendo como foco as relações entre os saberes da formação inicial em Pedagogia, na concepção de duas professoras que tiveram formação em instituições distintas e atuam em diferentes contextos. A opção 
pela abordagem qualitativa se deu por considerarmos esse processo mais adequado ao problema proposto, tendo em vista que se caracteriza como "[...] uma abordagem naturalista, interpretativa, para mundo, o que significa que seus pesquisadores estudam as coisas em seus cenários naturais, tentando entender, ou interpretar, os fenômenos em termos dos significados que as pessoas a eles conferem". (DENZIN; LINCOLN, 2006, p. 17).

Tal abordagem se coaduna com as reflexões de Gatti (2007) sobre as pesquisas em Educação, quando afirma que elas não podem estar dissociadas de uma perspectiva social, visto que existe uma relação muito estreita entre a produção científica da área e as mudanças que ocorrem na Educação e na própria sociedade. Assim, a opção por esse tipo de pesquisa "[...] implica uma ênfase sobre as qualidades das entidades e sobre os processos e os significados que não são examinados ou medidos experimentalmente (se é que são medidos de alguma forma) em termos de quantidade, volume, intensidade ou frequência". (DENZIN; LINCOLN, 2006, p. 23).

Nesse sentido, o presente estudo preocupou-se com a complexidade de fenômenos humanos, relacionando-os ao contexto em que ocorreram, demonstrando, assim, uma preocupação com o processo e não apenas com o resultado das situações investigadas, buscando compreender o problema da investigação, em sua complexidade.

Para tanto, optamos por dialogar com duas professoras, por meio de entrevista semiestruturada, buscando conhecer suas percepções e reflexões sobre a questão proposta para o estudo. As entrevistas foram realizadas em local reservado e gravadas integralmente, para posterior transcrição e análise. Como identificação das professoras entrevistadas utilizamos uma identificação codificada, preservando as verdadeiras identidades. Assim, teremos os relatos de P1 (professora 1) e P2 (professora 2), ao longo da discussão dos resultados.

\section{Análise e discussão dos relatos da pesquisa: a voz que vem da sala de aula}

Diante da pesquisa realizada com as professoras colaboradoras, observamos que existem aspectos positivos e negativos sobre as influências do curso de Pedagogia nas práticas das professoras.

Para a entrevistada P1, os estudos realizados no curso de Pedagogia não foram suficientes para prepará-la para ser professora porque ela percebeu um distanciamento das teorias estudadas em relação às práticas escolares. Segundo 
a entrevistada, essa situação poderia ter sido sanada durante o Estágio, onde a teoria e a prática deveriam se entrelaçar, no entanto, mesmo a vivência do Estágio foi insuficiente para a preparação necessária à atuação como docente dos primeiros anos, como relata a seguir:

O Estágio que a gente tem também não ajuda muito. Quando os professores chegam na escola para dar aula, chegam com muitas dúvidas, não sabem por onde começar. Nos $3^{\circ}$ anos, por exemplo, os professores não sabem como lidar com a indisciplina, que é cada vez maior. Então, me senti muito frustrada no início. (P1).

Em sua fala, P1 afirma que há um distanciamento entre teoria e prática durante o curso que, segundo a entrevistada, fica evidente durante o Estágio, certamente pela dificuldade dos professores em lidar com a indisciplina dos alunos nas escolas, o que evidencia que essa situação se reflete nas dúvidas dos alunos quando começam a lecionar. Dessa forma, concorda que o papel da teoria é possibilitar a análise da prática para subsidiar a tomada de decisões na superação das dificuldades encontradas. (ROCHA, 2006).

Questionada ainda sobre o motivo de sua formação não ter sido suficiente, P1 remete a questão à falta de prática durante o curso que realizou porque, na sua opinião,

[...] no Estágio os alunos ficam mais preocupados em preencher corretamente as fichas e com a teoria do que com a prática. Também tem professor que não gosta de receber estagiário, ai fala que vai só assinar a ficha pra ele e tem gente que aceita. Tive muitos colegas meus que nem chegaram a fazer Estágio. (P1).

A professora atribui ao Estágio a responsabilidade pela ausência de prática na formação, ressaltando, desta forma, que os demais componentes curriculares são exclusivamente teóricos. Ainda sobre essa questão, P1 afirmou que o curso que realizou não lhe preparou para lidar com as situações do cotidiano da sala de aula "real", pois considera que a realidade é bem diferente da formação; em sua fala afirmou que a realidade das salas de aula nas escolas envolve turmas superlotadas e condições estruturais precárias e que falta conhecimento ao professor recém-formado para lidar com essas situações. 
Apesar disso, ao ser questionada se tinha dificuldades com algum conceito que ministrava, a professora asseverou que não, que dominava completamente os conhecimentos das disciplinas que ministrava, porém atribuía tal domínio à experiência de quase sete anos com a mesma turma e não às aulas que teve durante a formação inicial.

$\mathrm{O}$ relato de P1 demonstra que a professora não consegue relacionar os estudos teóricos da formação em Pedagogia ao cotidiano escolar, referindo-se especialmente aos conhecimentos que precisa ensinar, quais sejam, os conceitos científicos das diferentes áreas do conhecimento, como Matemática, Língua Portuguesa, História, Geografia e Ciências. Esta situação revela que, para P1, a formação inicial em Pedagogia não lhe preparou adequadamente para lidar com os conceitos escolares, configurando uma lacuna importante na formação. Observem que, para a professora, o conhecimento acadêmico é limitado a teorias, que se tornam obstáculos ao trabalho docente: "Todo professor fica um pouco frustrado com a formação, não é? Porque na faculdade não se aprende tudo o que precisa, é muita teoria e pouca prática, então quando o professor chega pra dar aula não está preparado." (P1).

Sobre essa questão, retomamos a discussão de Gauthier et al. (1998) sobre os saberes da profissão docente, em que o profissional não se constitui apenas por um aspecto da formação, suas experiências de vida são muito contributivas por meio dos saberes experienciais, além dos saberes pedagógicos, que advêm da formação, junto com os saberes disciplinares e da tradição pedagógica; além destes, ressaltamos os saberes da ação pedagógica, que são inerentes a cada profissional em sua trajetória profissional, entrelaçando os conhecimentos teóricos às vivências da prática docente no cotidiano em que atua.

A professora $\mathrm{P} 2$, ao contrário de $\mathrm{P} 1$, afirma que o curso de Pedagogia foi muito significativo e a ajudou a constituir-se como docente, embora reconheça que não saiu do processo formativo sem dúvidas. A justificativa para essa satisfação é atribuída por P2 ao fato de que ser professora foi uma opção consciente e ansiada desde muito cedo, pois além da mãe, outros familiares são profissionais dessa área:

[...] eu não escolhi Pedagogia por falta de opção. Eu escolhi Pedagogia porque eu sempre quis ser professora. Eu sou de família de professores [...], eu gostei do curso de Pedagogia, porque o curso de Pedagogia me deи embasamento para o que eи sou hoje. (P2). 
A fala de P2 demonstra que a opção pelo curso de Pedagogia foi uma decisão amadurecida desde a infância, pela influência de familiares; assim, em outro momento da pesquisa, a entrevistada relata que esse fato a ajudou a se envolver com o curso desde o início e que outras colegas tiveram outros motivos para realizar o curso, então sentiam mais dificuldades em compreendê-lo:

[...] eu não tive tanta dificuldade de entrar em sala, porque eu sou de família de professores. Então, ver a minha mãe dar aula, ver a minha mãe planejar era muito normal. isso pra mim era... rotina. Isso era normal na minha vida, muitas vezes eu ficava em sala de aula ajudando minha mãe a dar aula de reforço. Agora uma pessoa que, do nada, pensa em fazer Pedagogia por falta de opção tem problemas em acompanhar. A maioria é assim. Lembro que, no meu primeiro dia de aula na faculdade de Pedagogia, em 2002, um professor sentou a gente num círculo e foi perguntando um por um. A pergunta dele não era por que a pessoa estava fazendo aquele curso, a pergunta dele era: "Qual o curso que você queria fazer e não conseguiu?" Se for muito, cinco falaram que sempre quiseram Pedagogia, todas as outras estavam fazendo Pedagogia porque não tinham opção. (P2).

Nesse aspecto, podemos dizer que o relato de $\mathrm{P} 2$ revela que a busca pelo curso de Pedagogia ocorre mais como falta de opção dos alunos que ingressam nesse processo formativo do que por interesse próprio; isso demonstra que a profissão não é atrativa para as pessoas e, ao tornar-se uma opção secundária, certamente, implicará em uma influência negativa na forma como os alunos lidam com os saberes da formação, tanto no decorrer desta quanto após a conclusão do curso e entrada no mundo do trabalho, que precisa ser analisado e valorizado.

No que tange aos conhecimentos que ministra em suas aulas, P2 afirmou que os considera complexos sim, especialmente os conhecimentos de Matemática, porque sempre teve muitas dificuldades com essa disciplina e que, em razão de sua experiência negativa com os conceitos de Matemática, não consegue trabalhar com turmas de $4^{\circ}$ ou $5^{\circ}$ anos, que exigem mais habilidades do professor com os conceitos que tem que ensinar. E, a seu ver, o curso de Pedagogia não lhe possibilitou superar as dificuldades com essa disciplina, porque teve poucos estudos específicos durante a formação.

A entrevistada também afirma em sua fala que o curso de Pedagogia tem mais teoria do que prática, porém, ao contrário de P1, P2 não vê esse aspecto como negativo e justifica da seguinte forma: 
Porque eu acredito muito na teoria e prática. Eu não acredito só na prática. Tem que ter uma fundamentação de tudo o que eu faço, eu não faço meu trabalho do nada. Tem que ter um porquê. Então, muitas colegas de formação não aceitavam essa situação, de ter que estudar Paulo Freire, Vygotsky, Piaget, por exemplo, queriam mesmo que os professores dissessem como dar aula, ao que eles se negavam, afirmando que não era esse o papel deles na formação. (P2).

Nesse trecho da fala de P2, é possível perceber que durante a formação os alunos querem aprender a "dar aulas", desconsiderando a necessidade de estudos teóricos para realizar uma boa prática. Entretanto, pode indicar também que os professores do curso de Pedagogia não consideram relevante ampliar as vivências durante a formação.

Diante dos resultados, percebemos que a relação teoria-prática no curso de Pedagogia é uma questão que precisa ser muito investigada, na busca de compreender até que ponto as teorias se aproximam da realidade que será vivenciada pelos futuros profissionais, visando oportunizar ao futuro profissional conhecer e refletir permanentemente sobre o contexto de sua atuação, tendo sempre como referência a formação inicial.

\section{Considerações finais}

A formação dos professores precisa possibilitar aos futuros profissionais o conhecimento e as condições necessárias para assumir atitudes concretas em sua ação pedagógica, o que significa envolver saberes que interliguem o ensino, a aprendizagem, a pesquisa e as relações que permeiam o universo educativo. Neste sentido, os fundamentos de uma profissão são importantes para adequar as estratégias mais adequadas a cada situação, princípios que se discutem ainda no processo formativo.

Tardif e Raymond (2000), referindo-se às dificuldades dos primeiros anos de atuação pedagógica dos profissionais, em razão da incompletude de suas formações, acrescentam que:

O início da carreira é acompanhado de uma fase crítica, pois é a partir das certezas e dos condicionantes da experiência prática que os professores julgam sua formação universitária anterior. Segundo eles, muita coisa da 
profissão se aprende com a prática, pela experiência, tateando e descobrindo; em suma, no próprio trabalho. Ao estrearem em sua profissão, muitos professores se lembram de que estavam mal preparados, principalmente para enfrentar condições de trabalho difíceis, sobretudo do ponto de vista do interesse pelas funções, da turma de alunos, da carga de trabalho, etc. Foi através da prática e da experiência que eles se desenvolveram em termos profissionais. (TARDIF; RAYMOND, 2000, p. 229).

A formação dos professores, então, requer um aprendizado permanente; logo, os saberes da formação inicial dos docentes são fundamentais para que a educação se renove com ações conscientes em torno das práticas e dos olhares que envolvem os conceitos escolares e a apropriação destes pelos alunos.

Ao considerar a formação de professores como o momento da apropriação dos saberes que fundamentam a prática dos profissionais da Educação, é possível pensar nela como um processo multidimensional. Nesta perspectiva, é preciso envolver a diversidade de conhecimentos que possibilite aos educadores uma atuação consciente, transformadora e crítica com seus alunos.

Partindo dessa premissa, a forma pela qual os professores envolvem conceitos e técnicas, no momento da aula, pode colaborar para a construção do conhecimento dos alunos como crítica ou não. A formação de professores, neste sentido, consiste em um aprendizado permanente, que exige uma transformação interior de cada sujeito envolvido para consolidar um trabalho duradouro.

Libâneo (2010) afirma que há uma necessidade premente de reformulação dos currículos do curso de Pedagogia, especialmente no que tange às discussões inerentes às disciplinas escolares - Língua Portuguesa, Matemática, História, Geografia e Ciências -, de forma que os conhecimentos ausentes na formação sejam articulados a metodologias adequadas das disciplinas que as(os) futuras(os) profissionais irão ensinar às crianças. Ele considera que:

Vive-se no Brasil, no âmbito da formação de docentes, um estranho paradoxo: professores dos anos iniciais do Ensino Fundamental, que precisam dominar conhecimentos e metodologias de conteúdos muito diferentes, como Português, Matemática, História, Geografia, Ciências e, às vezes, Arte e Educação Física, não recebem esses conteúdos específicos em sua formação, enquanto que os professores dos anos finais, preparados em licenciaturas específicas, passam quatro anos estudando uma só disciplina, aquela em que serão titulados. (LIBÂNEO, 2010, p. 580-581). 
A partir desse ponto de vista, se faz necessário uma profunda reflexão sobre os currículos do curso de Pedagogia, com vistas a aproximar essa formação da área de atuação dos profissionais que nele se formam. Isso não significa que as teorias estudadas precisam ser descartadas, mas, sem dúvida, há que se ampliar as possibilidades de estudos pertinentes aos conceitos que são ministrados nos primeiros anos do Ensino Fundamental pelos professores desse segmento, objetivando gerar um equilíbrio entre fundamentos pedagógicos e específicos da ciência.

\section{REFERÊNCIAS}

CICILLINI, G. A. Professores universitários e sua formação: concepções de docência e prática pedagógica. In: NOVAIS, G. S.; CICILLINI, G. A. (Org.). Formação Docente e Práticas Pedagógicas: olhares que se entrelaçam. Belo Horizonte: Junqueira \& Marin: Fapemig, 2010.

CUNHA, E. R. Os saberes docentes ou saberes dos professores. Revista Cocar, 2007. Disponível em: <http://www.virtual.ufc.br/solar/aula_link/lmat/A_a_H/didatica_I/ aula_01-1670/imagens/03/saberes_docentes.pdf $>$. Acesso em: 03 ago. 2013.

DENZIN, N. K.; LINCOLN, Y. S. A disciplina e a prática da pesquisa qualitativa. In: DENZIN, N. K.; LINCOLN, Y. S. O planejamento da pesquisa qualitativa: teorias e abordagens. 2. ed. São Paulo: Artmed, 2006. p. 15-41.

FIORENTINI, D.; COSTA, L. M. Enfoques da formação docente e imagens associadas de professor de matemática. Disponível em: $<$ http://siaiweb06.univali.br/seer/index.php/ rc/article/viewFile/178/150>. Acesso em: 24 out. 2009.

FREIRE, P. Pedagogia do oprimido. 23. ed. Rio de Janeiro: Paz e Terra, 2005.

FREIRE, P. Pedagogia da autonomia: saberes necessários à prática educativa. São Paulo: Paz e Terra, 2011.

GATTI, B. A construção da pesquisa em Educação no Brasil. Brasília: Líber Livro, 2007.

GATTI, B. Formação de professores no Brasil: características e problemas. Educação e Sociedade, Campinas, v. 31, n. 113, p. 1355-1379, out./dez. 2010.

GAUTHIER, C.; MARTINEAU, S.; DESBIENS, J.-F.; MALO, A.; SIMARD, D. Por uma teoria da pedagogia: pesquisas contemporâneas sobre o saber docente. Ijuí: Editora Unijuí, 1998.

LIBÂNEO, J. C. O ensino de Didática, das metodologias específicas e dos conteúdos específicos do Ensino Fundamental nos currículos dos cursos de Pedagogia. Rev. Bras. Est. Pedag., Brasília, v. 91, n. 229, p. 562-583, set./dez. 2010. 
PAIM, E. A. Mapeando cânones contemporâneos de formação de professores. In: PAIM, E. A. Memórias e experiências do fazer-se professor (a) de História. Tese (Doutorado) Faculdade de Educação, Universidade Estadual de Campinas, Campinas, 2005. p. 82-145.

ROCHA, G. A. E agora... cadê os dragões? Uma pedagoga, mestre e doutora em educação, vai aprendendo a ensinar no exercício da profissão. In: LIMA, E. F. (Org.). Sobrevivências no início da docência. Brasília: Liber Livros Editora, 2006.

TARDIF, M. Saberes profissionais dos professores e conhecimentos universitários: elementos para uma epistemologia da prática profissional dos professores e suas consequências em relação à formação para o magistério. Revista Brasileira de Educação, n. 13, p. 6-24, jan./abr. 2000.

TARDIF, M.; RAYMOND, D. Saberes, tempo e aprendizagem do trabalho no magistério. Educação e Sociedade, Campinas, n. 73, p. 209-244, dez. 2000.

VYGOTSKY, L. S. A formação social da mente. 6. ed. São Paulo: Martins Fontes, 2003.

Texto recebido em 09 de fevereiro de 2016.

Texto aprovado em 27 de março de 2016. 